International Journal of Linguistics, Literature and Translation

ISSN: 2617-0299 (Online); ISSN: 2708-0099 (Print)

DOI: $10.32996 /$ ijllt

Journal Homepage: www.al-kindipublisher.com/index.php/ijltt

IJLLT

\title{
Audience and Purpose as a Guide to Improve Acceptability and Readability of Technical Translation
}

\author{
Pinfan Zhu 8 (iD) \\ Full Professor, English Department Texas State University-San Marcos, San Marcos, Texas, 78666 United States of America \\ $\checkmark$ Corresponding Author: Pinfan Zhu, E-mail: pz10@txstate.edu
}

\begin{tabular}{|c|c|}
\hline ARTICLE INFORMATION & ABSTRACT \\
\hline Received: June 11, 2021 & \multirow{8}{*}{$\begin{array}{l}\text { Equivalence theory in translation, which is source-text focused, has always been an } \\
\text { influential guideline for translators. However, recently, scholars argue that } \\
\text { equivalence in translation is not totally possible, and in the author's opinion, it is not } \\
\text { even necessary in many cases in technical communication. In this article, the author } \\
\text { tries to approach technical translation guidelines from a different angle, which is } \\
\text { purpose an audience-focused. The paper discusses how to improve and evaluate the } \\
\text { acceptability or readability of technical translation in terms of the expectations of the } \\
\text { audience and the need for the translation purpose. Taking a Traditional Chinese } \\
\text { Medical website as an example, the author points out that only by targeting the } \\
\text { audience's needs at the semantic, syntactic, textual, and content levels can a technical } \\
\text { translator produce effective technical translations accepted and appreciated by } \\
\text { readers. }\end{array}$} \\
\hline Accepted: July 17, 2021 & \\
\hline Volume: 4 & \\
\hline Issue: 7 & \\
\hline DOI: 10.32996/ijllt.2021.4.7.11 & \\
\hline KEYWORDS & \\
\hline & \\
\hline $\begin{array}{l}\text { Rhetoric, equivalence, translation, } \\
\text { audience, and purpose }\end{array}$ & \\
\hline
\end{tabular}

\section{Introduction}

To achieve a good translation, scholars of different schools posit different approaches. The most influential guideline has been the equivalence theory advanced by Eugene Nida who holds that a translator should seek to translate the meaning of the original in such a way that the TL (target language) wording will trigger the same impact (equivalent effect) on the SL (source language) audience as the original wording did upon the ST (source text) audience (Nida and Taber 1982). The equivalent theory is more source-text-focused without much consideration of the background information of the target language and culture. So, scholars later argued that equivalent effect is impossible to achieve (QianHu 1993), and the success of equivalent effect is only "illusory" (Newmark 1981). As a result, other scholars sought different approaches to the guidelines, such as the discourse approach, cultural approach, hermeneutic approach, and an interdisciplinary approach. However, in this paper, the author will not discuss these approaches or which of them is more rational than another. In his opinion, each approach contributes a reasonable and practical solution to the problem from a different perspective. In addition, rarely can a translator stick to one approach in translating a book or a long text. This is because one approach, while appropriate for one type of information or message or a communication situation, may appear very improper for another type of information or another communication situation. So, technical translators need to consider all the approaches as mutually complementary rather than mutually exclusive.

In this paper, the author will discuss his approach to translation guidelines from the perspective of the audience and purpose. In other words, he will discuss how to evaluate and improve the acceptability or readability of a technical translation in terms of the needs of the audience and the purpose of the translation. Since audience and purpose fall in the category of rhetoric, the author would consider himself as approaching translation guidelines from a rhetoric perspective. In fact, through many years' experience of composition teaching and translation practice, the author considers a translation process, to a great extend, resembles a writing process. The translation is also a rhetorical act because translators have to select the most appropriate translation approach and the most effective language form at the semantic, syntactical, textual levels, or other appropriate choices regarding what to be translated from the source text and how much to be translated from it. Thus, discussing translation guidelines from a rhetorical perspective is also appropriate. According to contemporary American rhetoricians Bizzel and Herzberg (2001), rhetoric is "the

\section{K C AL-KINDI CENTER \\ $R$ DFOR RESEARCH AND DEVELOPMENT}

Your gateway to world-class research

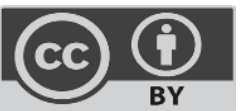

Published by Al-Kindi Center for Research and Development, London, United Kingdom. Copyright (c) the author(s). This open access article is distributed under a Creative Commons Attribution (CC-BY) 4.0 license 
strategies of effective oratory; the use of language, written or spoken to inform or persuade (p.1)." Since translators need to select the most effective language to make readers accept the translation and make them believe it is worth reading, so in this sense, it is a persuasive act, and it is because of this reason, discussing translation guidelines from a rhetorical perspective is of great appropriateness and value.

\section{A Few Words about Traditional Chinese Medicine (TCM)}

Prior to the discussion of TCM translation issues, the author provides a few words about Traditional Chinese Medicine (TCM) to give a reader a rough idea about what TCM is. In TCM theory, it is considered that there are two opposite sides in everything as well as in human boy: yin and yang. When the two sides are in a good balance, no trouble will occur. However, once the balance is lost because of one side prevailing over the other side, trouble comes into being. In this case, TCM tries various means such as using the medicine, which usually consists of leaves, barks, stems, roots of plants, herbs, etc., and acupuncture or massage to restore the balance so that the trouble is eliminated. If the trouble displays yang symptoms (e.g. swelling, heat, reddened tissue, etc.), medicines that are of cold properties are used to suppress the symptom. Otherwise, the treatment would be the other way around if the trouble displays yin symptoms. This is the guiding theory of yin and yang. In addition to the theory of yin and yang, TCM is also guided by another theory of five elements, which considers that, in light of the attributes of all the substances of the world, TCM classifies all things and major human organs into five elements: metal, earth, wood, water, and fire. Their relationships are like this: water nourishes wood; wood generates earth; earth generates metal, and metal generates water. The reverse relationships are like this: water conquers fire; fire conquers metal; metal conquers wood and wood conquers earth; earth conquers water. However, if the conquered element becomes too strong, it reverses the conquering. For example, too much fire may dry up the water. Based on these relationships of the five elements, TCM applies its therapy. For example, it assigns the five major human organs to the five elements: such as the kidney to water as it handles the water in the human body, and the heart to fire, as it handles the hot blood, and then, the liver to wood, the spleen to earth, and the lungs to metal. In this case, if the liver is in trouble, strengthening the kidney is necessary as water nourishes wood. To achieve this goal, treatments like acupuncture and medicine are used to strengthen the kidney while similar measures are used to replenish the liver if it displays yin symptoms (weak function); or suppress the inflammation if it displays yang symptoms. Of course, there are more detailed guidelines for such treatments guided by the two TCM theories of yin and yang and the five elements. So, correctly identifying symptoms is of priority in TCM in order to apply the right therapy. This is just a very brief introduction to TCM to give readers an idea about it. As TCM is a very cultural-specific element of China, which people from other cultures do not know about, using its translation to see whether a cross-cultural audience really understands it after reading its translated version would be effective to determine if the traditional approach to translation can really achieve its goal.

\section{Literature Review}

About Audience and Purpose: The term rhetoric has taken on a range of meanings over thousands of years. Rhetoric, in the Aristotelian term, is a faculty in each case to see the available means of persuasion (Aristotle 1991, 36). Nowadays, textbooks on writing tend to define rhetoric as the art of using language effectively. Part of Aristotle's important theory is his rhetorical triad that consists of logos, ethos, and pathos arranged in a triangle. Today, most American college students who take a composition class have to learn this rhetorical triangle. Professors tend to use a writer, a purpose, and an audience to represent the logos, ethos, and pathos respectively of the triad and teach their students how to construct the ethos of the writer (credibility or trustworthiness), how to use logos (logical reasoning and evidence) in the text, and how to appeal to pathos (the audience's emotion) in writing argumentation. Therefore, we can see even in Aristotle's time, audience and purpose had a place in rhetoric. In the late 50s of the last century, rhetoricians of the New Rhetoric School began to emphasize the role of the audience. Chaïm Perelman $(1982,145)$ distinguished three audiences: the audiences the speaker expressly addresses, the speaker himself, and the universal audience. He held that strategies used in an argument are determined by the nature and knowledge of the audience, as well as the purpose of the argument. In other words, translators need to target the audience's expectations and needs when creating text if they want to persuade the audience into accepting their translated views or ideas or causing them to show interest in the written or translated texts.

But in what aspects does the audience have control over the text to be created? Mainly, the audience affects our text in terms of the language level to be used, the organizational pattern, and the type of information to be included in the text. Needless to say, when technical translators translate or write for scholars and children, we need to accommodate them with different language levels and different types of information. A Russian translator Nabokov did a good job in accommodating different audiences when he translated Alice in the Wonderland for Russian kids and Eugine Onegin for the learned audience, which can be seen from his using an adaptation approach for child reading and an alienation approach (a translation approach that keeps the foreign features of the original text) for the educated. The adaptation approach makes the translation more acceptable to the audience while the alienation approach is more able to preserve the original flavor and let readers study the author's writing style and know the cultural message in the original works. So, different audiences need to be accommodated differently. Only in this way, translation works achieve acceptability, and the translator's effort reaches the translation goal. 
Regarding the function of purpose, Hans J. Vermeer advanced a more systematic theory of skopos (Greek for 'aim' or 'purpose'). He holds that a translatum is determined by its skopos. He states, "What the skopos states is that one must translate, consciously and unconsciously, in accordance with some principle respecting the target text" (Munday 2016, 126). Skopos theory focuses above all on the purpose of the translation. The purpose of the target text determines the translation methods and strategies in order to produce a functionally adequate or appropriate result. In fact, both audience and purpose have strategic control of our writing and translation, deciding what approach to take, what type of information to select, how much such information to include, what organization pattern to use, and what language style and level of difficulty to choose.

Here is an example, if someone has a bad experience with the use of a machine, s/he could write a narrative account of the event for his/her friends, or an informative report to the experts who made the machine, or an argument to the manager to replace the machine, depending on his/her different purposes, these different purposes of his/her writing would require him/her to select different information data, organizational patterns, language styles, and levels of difficulty because these different audiences such as experts, managers, and general readers would have different expectations for the writing. The same can be said of translation, people may use the same translation for different purposes. In light of this remark, technical translators could translate a book with different types of information, such as information about manufacturing time, cost, and process; about expertise to be used; and about technical specifications, functions, etc., by selecting the corresponding information that is of the reader's interest to accommodate his/her needs so that the translation is well accepted. I remembered at the 47 American Translators Association Conference (2016), a senior American translator told the author he normally did some editing to his translation to target the actual audience's need. In reality, we do have edited translations, condensed translations, adapted translations, abridged translations, truncated translations, and simplified translations for different translation purposes and different types of audiences. Just as Jeremy Munday (2005) points out, "One of the advantages of skopos (aim or purpose) theory is that it allows the possibility of the same text being translated in different ways according to the purpose of the target text and the commission which is given to the translator" (80).

Since audience and purpose are of importance to translators, it is necessary to identify the common audiences and purposes a translator may have for his or her translation. According to Markel (2017, p.81), an American composition professor, holds people who read technical information fall into four groups: people with strong expertise (experts and scholars), people with less expertise (technicians and repairmen), people without expertise (laymen and general public), and people who managerial jobs (managers and administrators. The purpose of the first-group people who read technical information is to study the equipment or machine so as to design or create new machines, improve the existing ones, or make use of the technical information for other technical purposes. People of this group will not mind jargon, long sentences, large blocks of text, abstract theories, or complicated and sophisticated diagrams that appear in the translated document. They normally do not have trouble interpreting the technical information translated by whatever translation approach.

The purpose of the second-group people who read technical information is to find information that helps them install, operate, service, or repair the machine. Too much jargon, abstract theory, or long sentences and bulky text blocks may intimidate them, cause trouble to them, or make them lose interest in reading. In translation, translators need to do some editing and revising that help reduce the above-mentioned difficulties so that the translation is well accepted.

The purpose of the third-group people who read technical information is possibly out of curiosity, personal interest, or to understand what the fun is of having such equipment.

Needless to say, the language used in translation should be simple. Translators need to use plain words, short sentences, and small text blocks, and interesting language as much as possible. Abstract theory, jargon, too complicated diagrams need to be avoided or revised to accommodate this group of people.

Finally, there is a special group of people who are managerial personnel or who make decisions in an enterprise. The purpose of this group of people who read technical information is possibly to know whether it is profitable to manufacture or purchase the machine. So, they are more interested in information about the expertise, time, cost, and manpower it takes to manufacture or use the machine. Translators need to select the relevant content for their translation so as to accommodate the needs of this group. Also, technical translators should try to use plain language and avoid difficult theory so that the translation possesses more readability for them (Kamen et al., 1999).

\section{Methodology}

To study the effectiveness of using audience and purpose as the guideline for technical translation so as to improve the acceptability and marketability of the translated works, the author focused on a case study as the main approach. The case is a TCM website that introduces TCM knowledge to cross-cultural or international laypersons. This is a good case to study how, when the audience and purpose needs of communication were ignored, technical translation may fail its goal as the audience has difficulty accepting the translated information as the research results (findings) showed. The main methods used include text 
analysis and interviews. These two methods are necessary because the use of language is decided by the choice of words, sentence patterns, and textual organization. For example, if a piece of technical translation aims at children as its audience, naturally, too many technical terms, difficult words, or words beyond children's reading comprehension, too complicated sentence structures or long sentences and indirect or inductive textual organization in a translated text are obviously inappropriate as children's intellectual maturity has not yet reached this deep extent. So, this explains why the author needs to start with the semantic, syntactical, and textual analysis to identify problems that occurred when the audience and purpose were not used as the guideline for the technical translation. Specific practice includes, through intensive reading, focusing on some words and studying them in terms of their semantic, technical, and stylistic effects in the text to evaluate their appropriateness in the text and decided their unsuitability for general readers. Then, the author went to the syntactical level to study the sentence effect in terms of difficulty level and stylistic results. The third step was to study the textual organization of information and content analysis in light of the audience's need to be yielded by their cultural preference to decide the effectiveness of the translated text. Along the way, the author also conducted a few interviews among some American acupuncturists to collect their comments on some translated text from the semantic, syntactic, and textual perspectives so as to triangulate the research result. These were the main methods employed to gain the validity and reliability of the study.

\section{Findings of Evaluating Translation Readability In Light of Audience and Purpose Needs}

With the reader's needs identified and also in light of communication purpose, translators can evaluate whether a piece of translation is readable or acceptable to their readers. To demonstrate, the author uses a case study of a translated website for this purpose. Some years ago, the author was doing cross-cultural communication research, and he was interested in websites created in English for an international audience. I went to a website of www.enwei.com created by Chinese people to introduce Chinese culture to Western readers. The website is a synthetic one that has various topics on Chinese culture. I was more interested in Traditional Chinese Medicine (TCM), so I clicked its link and saw a web page as follows:

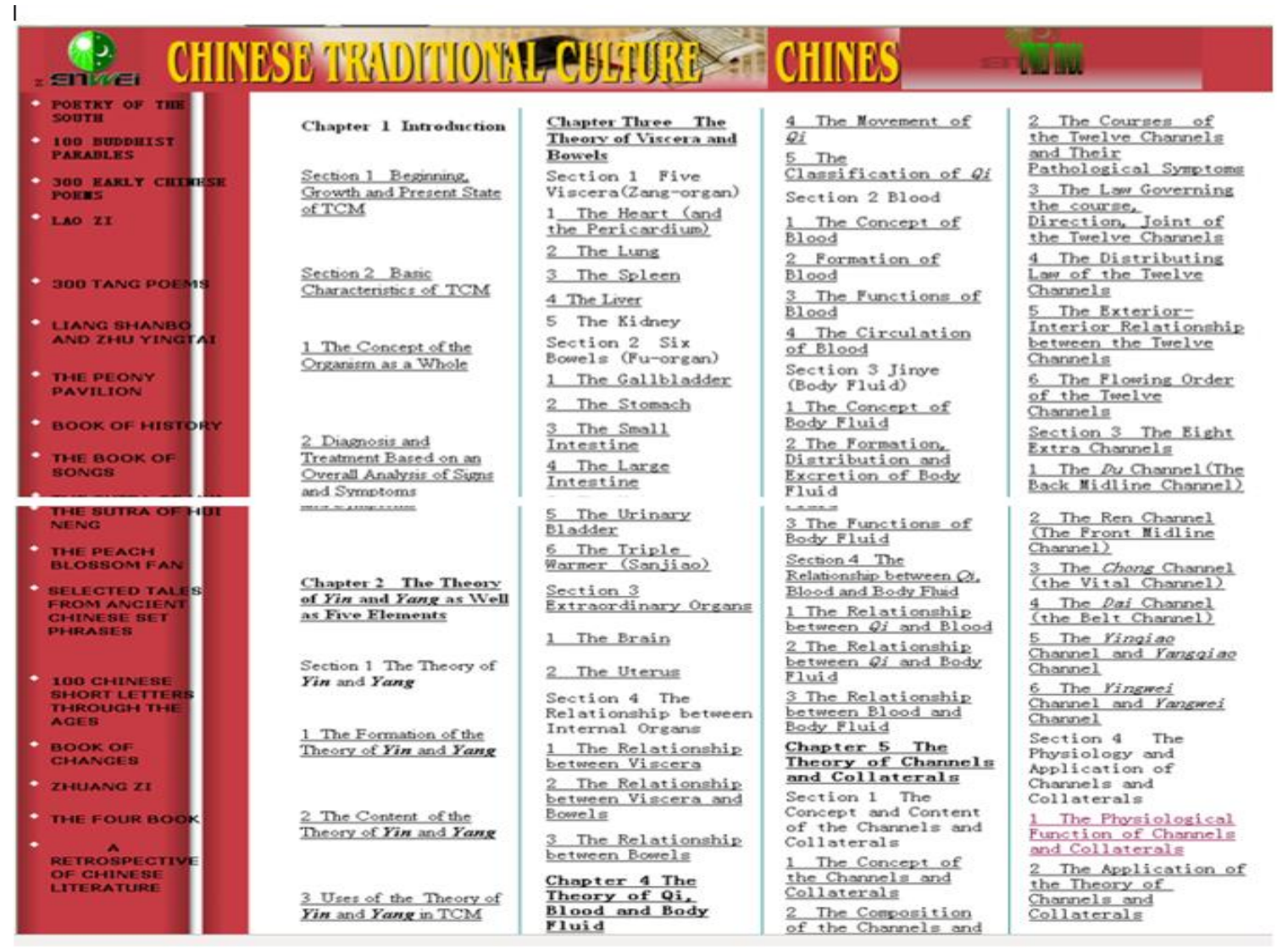

Figure 1. The Screen Shot of the Table of Contents (Enwei 2003).

The author was overwhelmed by the information on the page and was not sure for whom the information was provided. He called the webmaster who put him through to the manager of the translation team of the company. The latter told him that the provided online information was to introduce TCM to general Western readers. They selected a book on TCM and had it translated and 
published on this website. In light of the purpose and audience of the TCM web pages, the author examined the translated information and concluded that the translation had poor readability or acceptability for its audience. The conclusion was based on the following findings:

\subsection{Translated TCM Information Inappropriate in Terms Of Its Content-Type for Its Audience and Purpose}

As explained on the website, the purpose of the TCM website is to introduce basic knowledge of TCM, and the audience is a general Western reader. In light of the explained purpose and audience by the manager and the guidelines the author states above, he considers that the translated information should be elementary, relevant, concise, and interesting because the audience has no professional experience in TCM and his/her knowledge of TCM is practically zero. Moreover, as the audience is a Western reader, his/her knowledge of Chinese culture is limited. So, the information translated should be, above all, easy for him/her to read or accept. However, when reading the translated information, the author finds it to be short of the audience's expectations. First, much of the translated information is not the right type for the audience. Look at the following example taken from one of the web pages:

Ex.1: Traditional Chinese Medicine has now reached a new stage of development. On January 4, 1986, the State Council of the People's Republic of China decreed that the State Administrative Bureau of TCM and Pharmacy be established. This leading body exercises control over TCM and Chinese material medica, the step-by-step combination of Chinese and Western medicine as well as the medical teaching and research work of national medicine and pharmacy throughout China (Enwei, 2003).

Ex. 2: In China, quite a number of colleges of medicine and pharmacology and scientific research are undertaking the research on the essence of "Zheng"(syndrome) in TCM. For example, Chongqing Medical College holds that "Zheng" is the comprehensive manifestation of the disorderly relations, resulting from the pathogenic condition between the whole body and its reactive characteristics on one side and its surroundings (including nature and society) on the other, between viscera, bowels, channels, and collaterals, between cells themselves and between body fluid; that "Zheng" is a reaction of life substances characterized by time -phase and essentiality in the course of a disease; and that Zheng is a whole-finalized pattern of reaction which mainly manifest itself in the clinical functional changes. Other scholars believe, from the point of vague mathematics, that "Zheng" is a vague collectivity made up of such materials as symptoms, signs, and characteristics (Enwei, 2003).

The first example tells how the Chinese government helped establish an administrative body to administer the operation of TCM while the second involves an academic issue concerning Zheng and the opinions of different schools regarding it. Very likely, these two types of information are not suitable types for its audience since they are not of her/his direct concern. The audience may just want to have a basic knowledge of TCM. Translating the above information for them is a waste of time. A general reader reads the information mainly out of curiosity or interest, not for the purpose of commanding it. Discussion of the TCM issue and how the Chinese government controls TCM will not interest him/her. S/he needs basic TCM knowledge, such as what TCM is, what are its major treatment methods, and why it can cure disease. Translated information needs to target these needs of the audience if the translator wants to maintain his/her interest.

Second, the author finds the translated information has an inappropriate scope of TCM knowledge for its audience in terms of the knowledge scope or depth. Altogether, there are five chapters with 67 topics of TCM knowledge posted on 158 web pages. It would take the audience two days to finish reading them. But, the author wonders who, as a general reader, is patient enough to read these 158 pages by sitting in front of the screen motionlessly for two days. Online reading is characterized by skimming and skipping, for there is always something interesting online to attract the reader with only a few clicks away. What's more, online information is often dynamic with lots of hyperlinks, hot links, and hypermedia to attract the reader from what he/she is reading. Finally, reading on the screen is more tiring to the eyes. So, it is almost impossible to keep the reader viewing the information about 158 pages long. In this case, condensed translation or adapted translation would best suit the situation. In terms of the knowledge depth, the author finds most of the topics need to be deleted as they are too abstruse for the reader to understand. For example, lengthy theoretical discussion of yang and yin, of the five elements, of channels and collaterals, and of qi and body fluid, which covers hundreds of pages, is incomprehensible and unacceptable to the reader who lacks even the basic knowledge of TCM. The following is one such an example: 


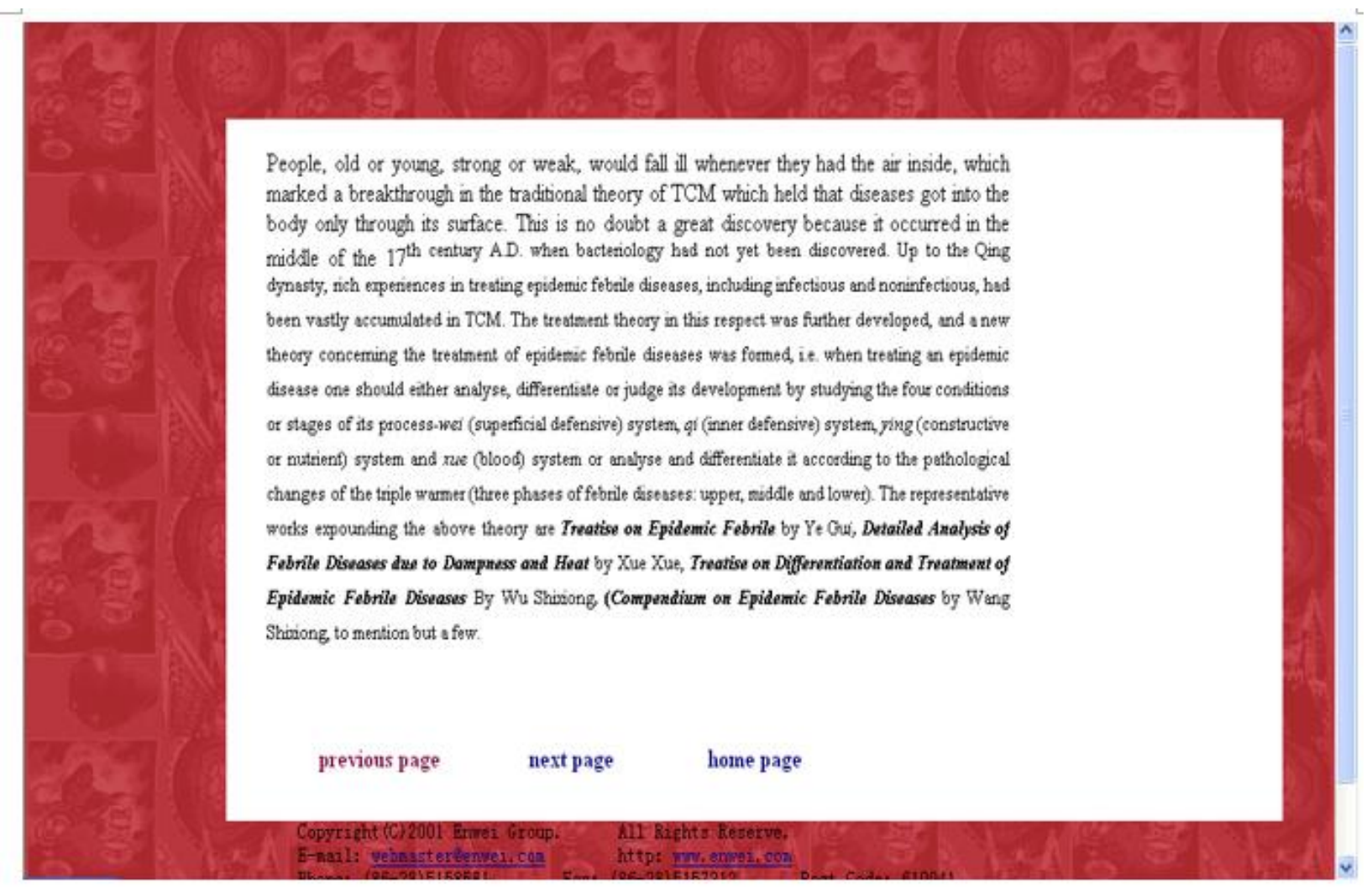

Figure 2. A Screenshot of the TCM Web Page (Enwei 2003)

The above example discusses how TCM treats febrile diseases (a kind of fever). The four conditions or stages of the process-Wei may seem only too difficult to a general Western reader. In fact, when the author distributed the text among several Ph. D. candidates in Texas Tech, they responded that the text appeared to be from a textbook on TCM, totally unsuitable for a layperson. So, in light of the audience's needs and the purpose of the web pages, we can see the translated TCM information has poor acceptability for its audience.

\subsection{TCM Information Translated in Language Stylistically Inappropriate for the Audienc's Needs and the Purpose}

When translating a technical document, translators need to choose words suitable to readers in light of their educational background or their professional knowledge. Experts normally do not mind jargon and long sentences. But general readers are different. They prefer simple or plain words when reading technical information because too many technical terms would baffle them, causing them to lose interest in the translated information (Markel 2017). So, choosing simple, easy words and avoiding jargon would increase the readability of the translated text for them.

5.2.1 Vocabulary with Stylistic Problem However, examining the web pages, the author finds many frustrating words and jargon on the first ten pages of online translation. Examples are:

febrile (feverish), anions (negatively charged ions), asthenia, (abnormal physical weakness) sthenia (vitality), medulla (inner region of an organ), pituitary (major endocrine gland), rostral and caudal (front and back),diuretics (causing increased passing of urine), micturition (urinating), borborygmus (noise from inside intestines), pectaoral, (relating to chest), anovulatory (ovulation fails to occur ), moxibustion (burning of moxa near the skin),sternocostal(chestwall pain), senislism (premature old age), fossa (hollow), malleolus (protruding part of ankles), rhizome (growing underground stem), atractylodis (side effect), macrocephalae (black rhizoma), arillus (an herb), cornus (a genus of shrub), moschus (musk oil), semen litchi (lichee kernel), succinum (amber), glycyrrhizae (species in the legume family), coptidis (goldthread flowering plant native to China), ephedrae (shrub-like plant native to central Asia), sargassum (a kind of seaweeds), sinensis (source of tea leaves), astrayliseu (of a star), papilla (a small flesh projection on a part of the body), and mammae (the breast). 
Different audiences need to be accommodated with the vocabulary of different levels. The general public prefers simple, plain words, but many words used on the TCM pages as shown above are very difficult words. Even the four Ph. D candidates from the English Department of Texas Tech interviewed did not understand them at all. The author looks at them in Yatsen English-Chinese Medical Dictionary that 130,000 entries, published by Chinese Foreign Languages Research Press, especially for medical scholars but fails to find most of the words. According to "Figures and Facts about the English Language," average people use 1,200 to 2,000 words for communication on most occasions. A native speaker knows about 12,000 to 20,000 (Bell Team, 2016) Shakespeare used more than 30,000 words in his works (Braven 2004). From this statistic, it may be inferred that a general reader's vocabulary should be much fewer than 20,000 words. But the words listed above are beyond the scope of any dictionary for general readers. In this case, we can possibly say that a general reader may not understand those words. The education non-professionals of TCM have received possibly does not allow them to read such a highly technical text with ease. In this sense, the author has to say the TCM text is not suitable for general readers with their cultural, TCM, and professional knowledge background.

5.2.2 Syntactical Problem In addition to the words used, the sentences used in the translated TCM text are also difficult to understand because of their long and complicated nature. Here are some examples:

For example, Chongqing Medical College holds that "Zheng" is the comprehensive manifestation of the disorderly relations, resulting from the pathogen and pathogenic condition between the whole body and its reactive characteristics on one side and its surroundings (including nature and society) on the other, between viscera, bowels, channels, and collaterals, between cells and body fluid; that "Zheng" is a reaction of life substances characterized by time-phased and essentiality in the course of a disease; and that "Zheng" is a whole-finalized pattern of reaction which mainly manifest itself in the clinical functional changes (Enwei 2003).

In light of the theory of five elements, TCM has made a comprehensive comparison and study of all kinds of things and phenomena in nature as well as in viscera, bowels, tissues, physiology, and pathology of the human body, attributed then respectively to one of the five elements, i.e. wood, fire, earth, metal, and water in accordance with their different properties, functions, and forms, thus expounding the physiology, pathology of the human body and the correlation between man and his natural surroundings (Enwei 2003).

In the light of research on the kidney by a special group at The First Medical College in Shanghai who studied this organ, it has been found that any of the following six different diseases: anovulatory and functional uterine bleeding, bronchial asthma, toxemia of pregnancy, coronary atherosclerotic heart disease, lupus erythematosus, and neurasthenia, is present with low 17hydroxycorticosteriod if the yang of the kidney is diagnosed to be deficient (Enwei 2003).

All of these sentences have more than 70 words, and the longest one has 90 words. They are very, very difficult for general readers. According to Rudolf Flesch (2000), a famous linguistic expert who once did a statistical analysis on the relationships between the length of sentences and the styles in The Art of Plain Talk, average sentence length in words for different styles are manifested as follows:

\author{
Very easy (easy prose, mostly dialogue): 8 words or less \\ Easy: 11 words \\ Fairly easy: 14 words \\ Standard (average reader): 17 words \\ Fairly difficult (literary English): 21 words \\ Difficult: 25 words \\ Very difficult (scientific English): 30 words or more (38)
}

By these standards, the sentences above are extremely difficult because they surpass the limit by such a great disparity. In fact, in addition to finding these terribly long sentences, the author did a rough estimation about other long sentences: from Chapter 1 to Chapter 3, sentences that have more than 30 words (covering three and a half lines, each line having 15 words) make up about 30 percent of the total texts. George A. Miller (1956) suggests that humans can process or hold in memory about seven (plus or minus two) items of information at a time (81-97). With a sentence that has more than 45 words, there should be more than seven items of information to be processed if an information item is to be defined as a different concept. In this case, the reader has to constantly return to the beginning of the long sentence and to re-read all the information items again and again to remember them. This is one of the reasons why long sentences are difficult. Another reason is that long sentences usually have complicated logical relations or grammatical relations among their members of the sentence. Without understanding these relationships, a reader is liable to confuse the intended meaning expressed. But to understand these relationships means time-consuming analysis. A general reader will possess neither enough expertise nor enough time for this time-consuming practice. So, the sentence structure is most unsuitable for a general reader who reads technical, especially medical, information merely out of curiosity or 
interest. The result is that $s / h e$ will lose interest in or become bored with such tedious information, and the translation will lose its significance. So, sticking to equivalent translation criteria obviously fails to accommodate the audience.

In addition to the unreasonably long sentences, there are also sentence patterns that are not quite reader-friendly to general readers because they are not organized according to the conventional thought pattern of the target readers. When the author was interviewing some American acupuncturists in the Emperor's College in Los Angeles, he asked questions concerning different aspects of the TCM documents those professionals had read. One of the questions the author asked was concerned with the organization of ideas, for which he received feedback from Noel Basby (2004), an intern with a master's degree, who said, "The English is not translated or written in the way we can just read and understand it. We have to rework it in our brains, and what I usually do is reorganize it and make charts in the language that I understand." Another acupuncturist, Lesley Moorcrofa (2004) also said, "They (texts) are not easy to understand because they don't follow the pattern you expect them to do." She concluded, "Organization of ideas is the problem that makes the text difficult for the Westerners."

The following is a paragraph that has improper sentence patterns:

Take lung trouble for example. If it results from heart trouble, that is regarded as "fire subjugating metal." If it is caused by liver (wood) trouble, that is referred to as "wood reversibly restricting metal." If it is led by the spleen (earth), trouble, that is looked upon as "illness of mother-organ involving son-organ." And if it is due to kidney (water) trouble, that is taken as "illness of son-organ involving mother organ" (Enwei 2003).

The paragraph is full of periodic sentences that have the main point delayed until the end of the sentence, so it is inductive in nature, not like a loose sentence that has the main point going first (e.g. He did not show up because he was ill). And this sentence pattern is typical in Chinese. That's why the author finds almost all the sentences that have a subordinate clause introduced by when, if, because, as, and though were translated in the original periodic sentence pattern, which is the result of following the equivalent approach. However according to David Megginson (2004),

Loose sentences are the most natural for English speakers, who almost always talk in loose sentences; even the most sophisticated English writers tend to use loose sentences much more often than periodic sentences. While a periodic sentence can be useful for making an important point or for a special dramatic effect, it is also much more difficult to read, and often requires readers to go back and reread the sentence so that by the end the reader has forgotten the main point is.

So, in light of this quote, the translator can better accommodate their general readers by sticking to their conventional discourse pattern. In fact, one of the interviewees, Brown Marilyn (2004), feeling uncomfortable with a paragraph full of the point-delayed sentences shown to her, revised it as follows:

Original: It analyses and differentiates febrile diseases according to the theory of six channels miscellaneous diseases according to the pathological changes of viscera and bowels and their interrelation, and in so doing establishes Chinese medicine's theoretical system and therapeutic principle, i.e., diagnosis and treatment based on an overall analysis of signs and symptoms. It lays a foundation for the development of clinical medicine (Enwei 2003).

Revised: The book analyzes and differentiates two groups of diseases: febrile and miscellaneous. In the former, the theory of six channels is discussed. In the latter, pathological changes of the viscera and the bowels, as well as their interactions, are discussed. This work establishes the theoretical system and the therapeutic principles of Chinese medicine. Also, this study lays the foundation for the development of clinical medicine (Personal communication, October 23).

It is not difficult to see that the revised version appears more linear and smooth than the original translation, and with this revised version, the reader can be better accommodated. Kirk St.Amant (2006) points out, "Recent research involving translation has indicated that even when reading or speaking in another language, the reader or speaker still prefers the rhetorical patterns of his or her native culture and even judges the effectiveness of other language documents according to their cultural rhetorical expectation" (298). This instance shows that native speakers prefer their conventional discourse pattern, so, to increase the acceptability of their translation, translators need to reorganize the original syntactic pattern so as to target the audience's needs. Otherwise, the reader will not feel comfortable reading the translated version if it follows a quite different sentence pattern from his/her conventional one. In other words, a reader can achieve better efficiency if reading in a familiar environment. To provide a reader with a familiar environment is to increase the readability or acceptability of a translation. The foregoing examples show how the reader is poorly accommodated in terms of the translated information scope and the difficult language used. 
5.2.3 Problems at the discourse level A main problem with the organization, according to Ron Scollon (2008), an intercultural communication theorist and a linguist, is that different cultures have their conventional discourse patterns. If a different discourse pattern is used which is not the conventional one of the audience, he/she may have difficulty in following the discourse. Scollon holds that Americans tend to use a deductive pattern to organize their discourse in which points come before supporting details, while Chinese people tend to use an inductive pattern in which supporting details come before the point. The point is that when an American audience hears a speech given by a Chinese speaker that follows his/her inductive pattern, the American audience may have trouble grasping the main points because $s /$ he uses the American discourse pattern to decode the speech. In this case, the Chinese speaker seems to beat about the bush to the American reader, which is a typical communication style of high-context people and is hard to follow for an American. Another scholar, Robert Kaplan also confirms this deductive discourse pattern of Americans by using another term "linear pattern."

Robert Kaplan (1967) in his landmark essay that pioneered contrastive rhetoric, "Cultural Thought Patterns in Intercultural Education," identified five rhetorical patterns through his examination of English as a Second Language (ESL) writings. This diagram shows how a native English speaker would characterize the writing of non-native writers of English as a second language. Kaplan provided a diagram of these patterns as follows:

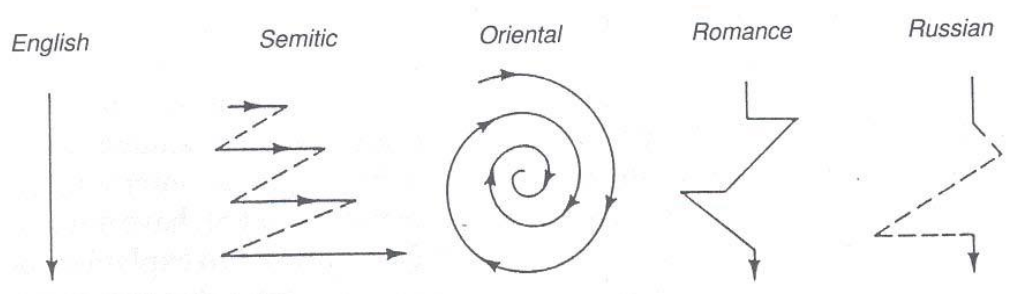

Figure 3. Kaplan's Diagram of Rhetorical Patterns. (Kaplan 1967)

A linear pattern means a discourse pattern that has points first and supporting details next and is straightforward with no "beat about the bush," but non-native speakers or translators, when they translate the text, still tend to follow their conventional inductive or indirect discourse pattern rather than a linear pattern, which makes reading difficult to a native speaker. Examining the translated TCM text, the author did find this problem exists at the discourse level. Here is an example:

In about the $11^{\text {th }}$ century A.D. Chinese medicine began to use the variolation method to prevent smallpox, thus becoming the pioneer of immunology in the world. From the $17^{\text {th }}$ to $19^{\text {th }}$ century A.D., infectious diseases spread continually. The School of Epidemic Febrile Disease appeared and grew in the struggle against them. Wu Youxing, a medical man of this school in the Ming dynasty, thought that the onset of an infectious disease was not due to wind or cold or summer heat or dampness, but due to impure, noxious atmospheric influences, which he called foul and evil foreboding air (epidemic noxious factor). He pointed out that this foul and evil-foreboding air got into the human body by way of the mouth and nose. People, old or young, strong or weak, would fall ill whenever they had the air inside, which marked a breakthrough in the traditional theory of TCM which held that diseases got into the body only through its surface. This is not doubt a great discovery because it occurred in the middle of the $17^{\text {th }}$ century A.D. when bacteriology had not yet been discovered. Up to the Qing dynasty, rich experience in treating epidemic febrile diseases, including the infectious and the noninfectious, had been vastly accumulated in TCM. The treatment theory in this respect was further developed, and a new theory concerning the treatment of epidemic febrile diseases was formed, i.e. when treating an epidemic disease, one should either analyze, differentiate, or judge its development by studying the four conditions or stages of its process-wei (superficial defensive) system or analyze and differentiate it according to the pathological changes of the triple warmer (three phases of febrile diseases: upper, middle, and lower). The representative works expounding the above theory are Treatise on Epidemic Febrile by Ye Gui, Detailed Analysis of Febrile Disease Due to Dampness and Heat by Wu Shixiong, and Compendium on Epidemic Febrile Diseases by Wang Shixiong (Enwei 2003).

At the beginning of the paragraph, the writer states, "In about the $11^{\text {th }}$ century A.D. Chinese medicine began to use variolation method to prevent smallpox, thus becoming the pioneer of immunology in the world." This sentence seems to be the topic sentence of the paragraph and accustomed to the linear organization pattern, an American reader would probably expect the paragraph to discuss how TCM was so smart in immunology, and what specific theory and methods were there for the immunization. But the paragraph does not develop in that way. Instead, it immediately switches to the $17^{\text {th }}$ century and starts to talk about Wu Youxing's discovery of disease causes and its significance but never mentions how this discovery is used for the immunization of diseases. After this, it discusses the rich experiences in treating epidemic febrile diseases and the new theory in 
this respect. The paragraph ends in a few book names that expound on the theory. So, the connection between the "topic sentence" and the body supporting details is not a close one. And even though the paragraph is focused on the treating theory on febrile disease, it still does not have points on which other details are developed. So, it is indirect in the organization.

Look at another example:

From the Qin and Han Dynasties (221.B.C.- 220 A.D.) doctors in the interior of China begins (began) to prescribe more and more rhinoceros horn (Cornu Rhinocerotis) amber (Succinium), antelope's horn (Cornu Antelopis), and musk (Moschus) from the minority nationalities; longan pulp (Arillus Longan), Lychee-seed (Semen Litchi) from the South China Sea and medical materials from Southeast Asia and other regions as a result of ever-developing communications and transportation both inside and outside of China. This enriched the Chinese people's knowledge of medicine (Enwei 2003).

This paragraph discusses how the knowledge of medicine is enriched in TCM, but the main point is delayed until the end of the paragraph. The specifics that lead to the conclusion include doctors' prescription of more kinds of drugs and more sources of drugs because of ever-developing transportation. The pattern is, because of $A$ and $B$, thus $C$, a typical inductive process. Thus, the TCM website has poor acceptability for its audience and fails its communication purpose. Specifically, the website fails because the translation has a poor selection of the right type of information, goes too deep or wide in terms of the TCM knowledge scope, and does not employ the right language style at a semantic, syntactical, and discourse level.

In fact, the manager said that the web pages (or the online book) only lasted half a year and were taken down because of the poor hit count. The case warned technical translators of the importance of audience and purpose awareness in technical translation if they want to increase the readability or acceptability of the translated work.

\section{Discussion}

This translation case the author discussed in the foregoing sections shows the important role of communication purpose and audience's needs in translation as they have a decisive role to play in producing readability and acceptability of a piece of translation. Briefly speaking, purpose and audience have strategic control over a technical translator's approach to translation. This control is mainly reflected in the choice of the type of information to be translated and how much information to be translated in terms of the audience's professional, educational, and cultural background, as well as what language style and language level technical translators should employ in translating and whether they should balance more to adaptability approach or alienation approach to the translation work at hand. Translation, to a great extent, is a rhetorical act that requires technical translators to make different choices at the semantic level, the syntactical level, and the discourse level if they want to increase the acceptability to better accommodate their audience, for rhetoric can be defined as a way of organizing words, sentences, paragraphs, and content in a particular way in light of our audience's needs and the communication purpose to affect an audience positively. In this sense, it can be said that technical translation needs to have its own translation guidelines if it aims at cross-cultural or international audiences, not following blindly the equivalent theory as proposed by Nida. Of course, more studies will be needed to strengthen this conclusion, and more cases should be needed as well, and being short of this might be considered as the weakness of this study.

\section{Conclusion}

On the whole, if a piece of technical translation wants to improve its acceptability or marketability, the needs of the targeted audience and the communication purpose should be given full attention. If the author may use a metaphor to describe the situation, translators should treat the SL text as a fish to be culinarily prepared to cater to people of different tastes. Some people do not like the fish head or tail or other parts so that the translator needs to take off these parts. Some people like the fish to be sweet and sour; others like the fish to be hot and spicy. Still, others prefer the fish to be prepared in a particular way, such as steamed, stir-fried, brewed, etc. So, a translator needs to make a corresponding response to these different tastes so that the fish can be sold and enjoyed by the customer. Definitely, adaptation is an area where a translator can bring his/her creative or rhetorical talent into play, which covers the type of message to be selected, the scope of information to be translated, the choice of word styles, syntactic patterns, discourse patterns, and the tone of the language. Translators need to choose the most suitable of all these to increase the acceptability and readability of their audience. However, more case analyses and statistics are necessary to confirm the conclusion, which might be the limitation of this research.

Funding: This research received no external funding.

Acknowledgments: My thanks go to all those who helped contribute comments and feedback for this article.

Conflicts of Interest: The author declares no conflict of interest.

\section{References}

[1] Aristotle. (1991). On Rhetoric: A Theory of Civic Discourse. (G. Kennedy Trans.). New York: Oxford University Press. 
[2] Bell Team (2016) How many words do you know? Retrieved July 23, 2019, from https://www.bellenglish.com/blog/how-many-words-doyou-know/

[3] Bizzel, P., \& Herzberg, B. (2001) The rhetorical tradition: Readings from classical times to the present. New York: Bedford/St. Martins.

[4] Braven, F. (2004). Figures and facts about the English language. Retrieved August 23,2004 from http://www.englishenglish.com/ english $\_$facts.htm.

[5] Brown. M (2004, October 23). Personal Interview.

[6] Enwei. (2003). Basic theory of Traditional Chinese Medicine. Retrieved August 5, 2003 from http://www.enweiculture.com/culture en/tcm1/

[7] Flesch, R. (1946). The art of plain talk. New York: Harper \& Brothers Publishers.

[8] Kamen, D et al, (1999). United States Patent 5, 971, 091 Retrieved January 21, 2015 from http://www.uspto.gov.

[9] Kaplan, R. (1967). Cultural thought patterns in intercultural education. Language Learning, pp. 8-20.

[10] Megginson, D. (1996). The order of a sentence. Retrieved August 20, 2004 from http://www.uottawa.ca/academic /art/writcent/hypergrammar/sntorder.html.

[11] Markel, M (2016). Practical strategies for technical communication. Bedford/St. Martin's.

[12] Miller, G. (1956). The magical number seven, plus or minus two: some limits on out capacity for processing information. The Psychological Review 63: 81-97.

[13] Mundane, J. (2016). Introducing translation studies: theories and applications London: Routledge.

[14] Newmark, P. (1981). Approaches to translation. Oxford: Pergmon Press.

[15] Perelm. C. (1982) The New Rhetoric: A treatise on argumentation, Indiana: University of Notre Dame.

[16] Scollon, R., and Scollon, W. (1995). Intercultural communication: A discourse approach. Oxford: Blackwell.

[17] St.Amant, K. (2003). When culture and rhetoric contrast: examining English as the international language of technical communication, Transaction on Professional Writing 56: 297-299. 